\title{
Integration of BIM in architecture and structural engineering education through common projects
}

\author{
K. Ajtayné Károlyfi ${ }^{1, *}$, D. Szalai ${ }^{2}$, J. Szép ${ }^{1}$, T. Horváth ${ }^{2}$ \\ ${ }^{1}$ Széchenyi István University, Department of Structural and Geotechnical \\ Engineering, Egyetem tér 1, 9026, Györ, Hungary \\ ${ }^{2}$ Széchenyi István University, Department of Architecture and Building \\ Construction, Egyetem tér 1, 9026, Győr, Hungary \\ *e-mail: karolyfi.kitti@sze.hu
}

Submitted: 23/07/2021; Accepted: 24/08/2021; Published online: 30/08/2021

\begin{abstract}
Building Information Modeling (BIM) is one of the most significant developments in architecture and civil engineering in recent years, therefore it becomes increasingly important to promote its integration into university education. Currently, several universities worldwide offer BIM courses in architecture and civil engineering programs, while many others are under the process of integrating BIM into their curricula. The goal of this research is the implementation of BIM into higher education (Széchenyi István University, Hungary) by integrating the architectural, structural, and mechanical engineering disciplines. An important advantage of the university is that the architecture and civil engineering programs belong to the same faculty, which allows students to work together on common projects. A new course was performed in the previous semester, in which the students are designing contemporary buildings as case studies. In this paper, the results of the integration process are presented and evaluated based on the trainers' and students' experiences.
\end{abstract}

Keywords: building information modelling; collaboration; higher education; project-based learning 


\section{Introduction}

The building industry of our accelerated world has demanded the digitization of architectural design and construction organization. Early digital design has begun to apply 3D modeling and then linked more and more information to the elements of the 3D model. In this way, Computer-Aided Design (CAD) has imperceptibly transformed into Building Information Modeling (BIM). The industry felt the effectiveness of the new method and found several other benefits as well. Thus, the newly formulated BIM concept has begun to reform the architectural design and construction. Standardization of the BIM methodology has begun worldwide [1]. In several countries, BIM-based planning is becoming mandatory depending on project size or funding. The Hungarian BIM national standard [2] was released in 2019, in which the application of this design method is highly recommended. Therefore, to prepare the students for the professional challenges of real life, the education must integrate this newly emerged methodology.

The Széchenyi István University (Györ, Hungary) has an important advantage because the architecture and civil engineering programs belong to the same faculty, which gives the possibility for students to work together on common projects. This research aimed to implement the BIM method into the curricula by integrating these two disciplines. In this paper, the integration process is presented and its advantages are evaluated and compared to the traditional building design education.

The university is a quite young educational institution, its ancestor was established in 1968. Civil engineers have been educated since 1974, and architects since 1990 (Fig. 1.). For today, the university has become an important regional higher education institution with nine faculties, and it makes efforts to increase its international recognition.

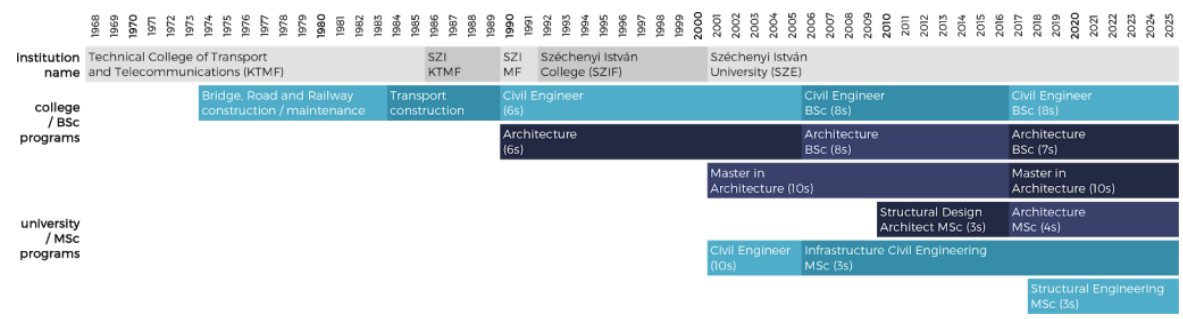

Figure 1. Civil engineer and architecture programs of the Széchenyi István University

Reformed programs started in 2017, as a result of a countrywide review of higher education. In the new curricula of the civil engineering and architecture programs, the education of the BIM method was inserted. Several courses refer to the different 
aspects of BIM, and dedicated courses were also introduced such as Structural BIM for civil engineers and BIM management for architects. Both courses belong to the 7th semester, which offered a great opportunity for joint training of the two disciplines. Teaching BIM requires a project approach and intensive teamwork. These techniques were used in both programs, but they appeared most intensively in the course of the Building Structure Design Project. We have been teaching these subjects for more than 10 years with good experiences. The BIM approach has often appeared in students' work, due to their interest [3]. In the new BIM course this approach has become mandatory and the key principle of the design process.

\section{Literature review}

There is a clear industry demand for engineers with advanced BIM skills, therefore its integration into higher education is crucial. There are three main ways for the implementation: (1) introducing BIM as an optional course or extracurricular activity, (2) introducing new BIM-related courses or implementing it into existing courses, (3) introducing an advanced BIM-related program, or any combination of the above. The implementation of BIM into academic programs is at different levels around the world. In the UK, many universities offer BIM-related courses in their AEC programs and at least 14 institutions have specific education programs due to the decisive government efforts to use BIM in public building projects $[4,5]$. In Australia, universities mainly offer BIM courses with special attention to teaching software skills. Similarly in the USA, more than half of the institutions offer courses with embedded BIM content [5]. In Hungary, the integration of BIM into AEC programs has begun in recent years, and already two institutions offer dedicated BIM programs.

The current practice of BIM education is very diverse according to the wide range of disciplines involved. In architecture education the documentation and visualization tools of the BIM is enhanced, while the structural engineering discipline is strongly connected to structural analysis and design software, the management discipline is more involved in the collaborative platforms of BIM and the construction-related subjects are usually dealing with scheduling, quantity statement and cost estimate. [6]. According to an extensive study of the NATSPEC [7], the proper use of the authoring software plays an important role in the current BIM education, while the implementation of open BIM and collaborative working environment is not receiving all the attention that it requires. Wang et al. [8] emphasizes the importance of the connection between BIM and other courses and recommend the adoption of BIM in the final semester project to integrate the previously acquired competencies. Based on the review and categorization of 70 publications from 24 countries made by Badrinath et al. [9], there is a clear trend 
towards the development of BIM curricula and educational frameworks, in which multidisciplinarity becomes a key factor.

The effective education of BIM methodology can be achieved by different methods such as self-study, web-based learning, project-based learning, lab tutorials, or lectures [4]. Baradi et al. [10] investigated studies on teaching collaboration within BIM education and identified the best practices. Results show that project and team-based learning is an effective way to teach collaboration skills, where students are assigned a project task to be fulfilled during the course. The learning process is the most successful when the task comes from live projects, where the entire design documentation is not available and it requires both team and independent work from the participants by considering alternative solutions as well. In this methodology, the trainers' role is mainly mentoring and guiding the process instead of teaching professional knowledge, where the involvement of industry mentors can contribute significantly to the development of practical skills $[4,11]$.

\section{Research method}

The research method includes three main steps: first of all, (1) the current education method of architectural and structural design was explored and evaluated by considering the industrial needs. Secondly, (2) the benefits of the BIM method were identified and the possibilities of implementation into the curricula were outlined by performing an educational pilot project. Finally, (3) the results of the implementation were evaluated by presenting the trainers' experiences and the students' opinions based on a questionnaire.

\section{The current state of architectural and structural design education}

The design-related courses of the university's architectural program are mainly using the traditional two-dimensional drawing methods. Generally, two main types of design tasks are present: (1) the entire building is designed by the student, or (2) an existing building is processed and redesigned based on the available plans published in a journal or on the Internet. In both cases, creating manual drawings is necessary for the beginning to develop or to understand the house, especially when designing an entirely new building. However, during the detailed design, the software is still used for creating two-dimensional architectural plans and technical specifications. The three-dimensional modeling is only a possibility for the students, which is mainly used for creating low-detailed visualization of the building independently from the plans. 
The structural design courses of the civil engineering program have a similar approach: in general, an existing building is processed based on the available architectural plans from different sources. The task begins with performing the preliminary two-dimensional structural plans, then a simplified finite element model is created, which is mainly planar or in some cases three-dimensional. The results of the structural analysis are mainly two-dimensional formwork and reinforcement plans, drawings of the structural joints, and construction plans.

The issues relating to other disciplines are usually discussed with the trainers of the course and consultation with specialists is also provided if necessary. Therefore there is no collaboration between students from different domains. However, the current practice requires strong cooperation between the project participants, which is rooted in the understanding of the significance of other disciplines [12]. With the implementation of the BIM method into higher education, these skills and abilities can be improved.

\section{Implementation of BIM into the curricula}

The basic idea of BIM is to create a common platform for cooperation among the disciplines [13]. The BIM model is the digital representation of the building, which is working as a shared knowledge resource for all of the project participants during the building's life cycle. In general, the architectural model is the basis of the project, which is used by the different professionals for their work. Each discipline adds specific data to the shared model, which information is directly accessible for the entire design team. Due to the nature of the method, BIM enables strong collaboration between the team members, which contributes to developing interdisciplinary thinking and skills. In 2020 the Structural BIM and BIM management courses were integrated for the civil engineering and architecture students to broaden their perspective and advance their understanding of the other's discipline. This educational pilot project was a simulation of the BIM working method, where the students are creating a common model, which will be the basis of further discipline-specific work. In this way, the civil engineering students gain skills in building construction design, while the architecture students learn how to create a model capable for structural analysis.

The education method was based on a mentoring scheme including short presentations connected to the main steps. The completed subtasks were discussed and evaluated in common lessons involving trainers from each discipline. On the trainer side, two BIM experienced architects (Kitti Ajtayné Károlyfi and Dóra Szalai), a building construction expert architect (Tamás Horváth), a structural and a mechanical engineer (János Szép, László Petrikó) helped the work. Students presented their work in progress plans every two weeks and received feedback and 
they had the possibility of weekly consultations. After the 10th week, the education was implemented in online form due to the epidemiological situation, however, the original system was kept.

In the newly introduced lecture, different buildings were selected from a construction-oriented architectural journal $[14,15,16]$ to ensure feasibility and give an interesting architectural and structural challenge to the students. Three groups were formed of four members including at least one architecture student and two or three civil engineering students. Each member was in the last or one before the last semester of their bachelor training.

The first group has chosen the Salt Office Building in Amsterdam (Fig. 2.a) designed by MVRDV [14], which is made of prefabricated reinforced concrete frame structure and framed facade panels with variously segmented glazing. The second building was the Freemen's School Swimming Pool (Fig. 2.b) near London [15] constructed from a large span laminated glued frame structure starting from a basement level with reinforced concrete structure. A smaller project, a single-family house (Fig. 2.c) in Tuttlingen [16] was chosen by the third group. It has an interesting asymmetric form, where the load-bearing structure is based on two reinforced concrete cross-walls, but the building envelope was made of lightweight timber construction.

In the course assignment, student groups had the task to design these buildings. Understanding the building began with the help of draft plans. From there, continuous development was performed until the detailed construction plans.

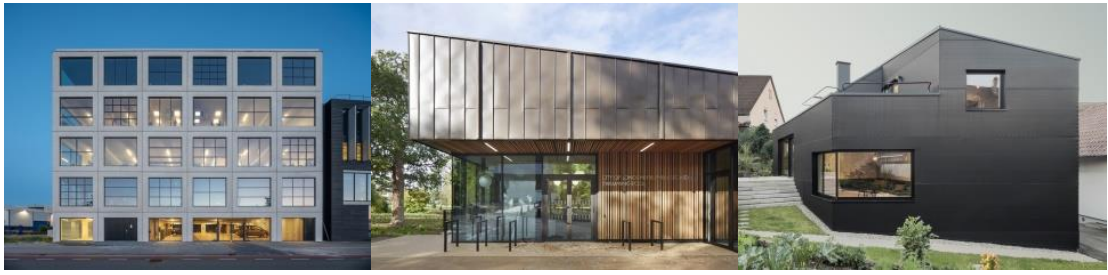

Figure 2. a) Salt office building in Amsterdam, designed by MVRDV, photo: Ossip van Duivenbode [14], b) School swimming pool near London, designed by Hawkins Brown, photo: Jack Hobhouse [15], c) Single-family house in Tuttlingen, designed by Yonder, photo: Brigida González [16]

The course description divided the whole design process according to the usual development stages designating both individual and group tasks. The design task was divided into the following parts:

1. Creating the architectural and structural model 
2. Improving LOD of the model

3. Structural analysis

4. Design of building structural details

5. Collision detection, quantity statements, and consignments

6. Preparation of the final documentation of the project.

The modeling process was started as a common task for each group member. The architecture students were responsible for the architectural and mechanical engineering model elements, while the civil engineering students for the loadbearing elements. From the 3rd step, the two disciplines had distinct subtasks, in which the feedback and communication have become even more important.

\subsection{Creating the architectural and structural model}

For the modeling of the buildings, the ArchiCAD 23 software was used. Three projects were created and shared on a BIMcloud server and the students were connected to the projects by using the teamwork function. The minimum level of information content for each object was the use of correct object type, position, material characteristic, and load-bearing function. This phase aimed to generate a model and automatic building permit design documentation at LOD 200, which means that the elements are modeled with approximate size, shape, and location (Fig. 3.).

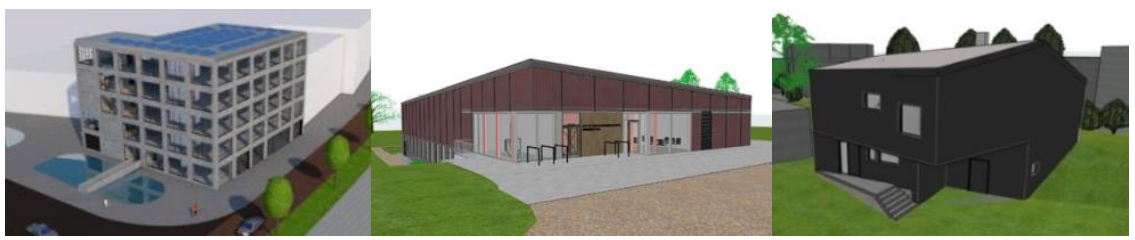

Figure 3. a) Model of the Salt office building [17], b) Model of the school swimming pool [18], c) Model of the single-family house [19]

\subsection{Improving LOD of the model}

The second step aimed to further development of the architectural and structural model to reach the LOD 300, in which the elements have the correct size, shape, and location and the main information content is also attached. Civil engineers prepared the model for export. Furthermore, a mechanical engineering model was also created including heating, plumbing, and air-conditioning systems at LOD 200 (Fig. 4.). 

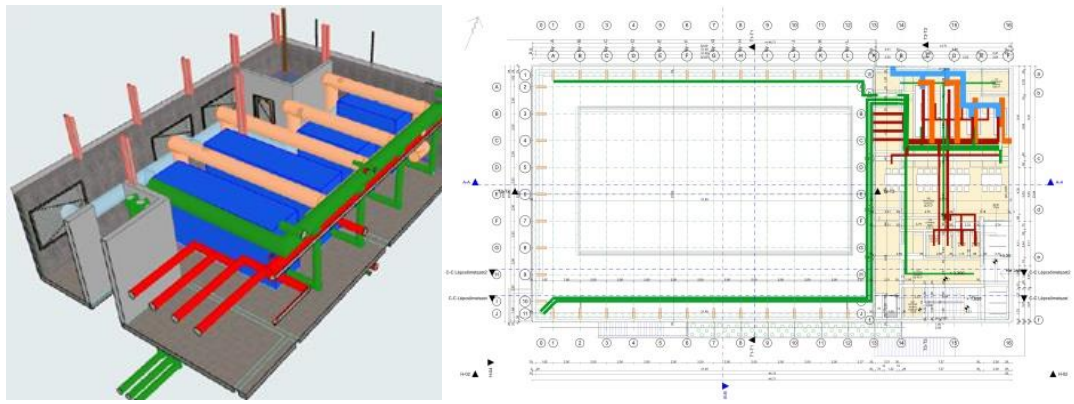

Figure 4. a) MEP model part and b) construction plan of the swimming pool [18]

\subsection{Structural analysis}

In the third phase, the civil engineering students have exported the structural models from ArchiCAD (Fig. 5.a) using an IFC translator. After the determination of the loads, the AxisVM software was used for the structural analysis, in which the cross-sectional dimensions and deformations of structures were checked (Fig. 5.b) and the reinforced concrete elements were designed in detail. After calculating the required reinforcement area, the used relative steel quantities were imported into ArchiCAD as an IFC attribute for each object. After that, students were able to create reinforcement quantity estimation for the whole building and develop the reinforcement plan of the main elements.
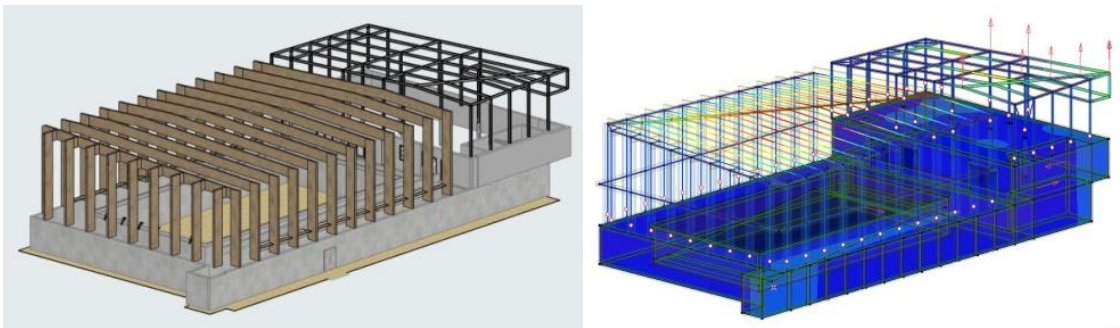

Figure 5. a) Structural model of the swimming pool in ArchiCAD 23, b) Result of the structural analysis in AxisVM [18]

\subsection{Design of building structural details}

After updating the model with the correct cross-sections based on the structural analysis, the detailed design of the construction joints was started. Architecture students worked on the building structural details (Fig. 6.a), while civil engineering students made calculations and plans for the main structural joints (Fig. 6.b). 

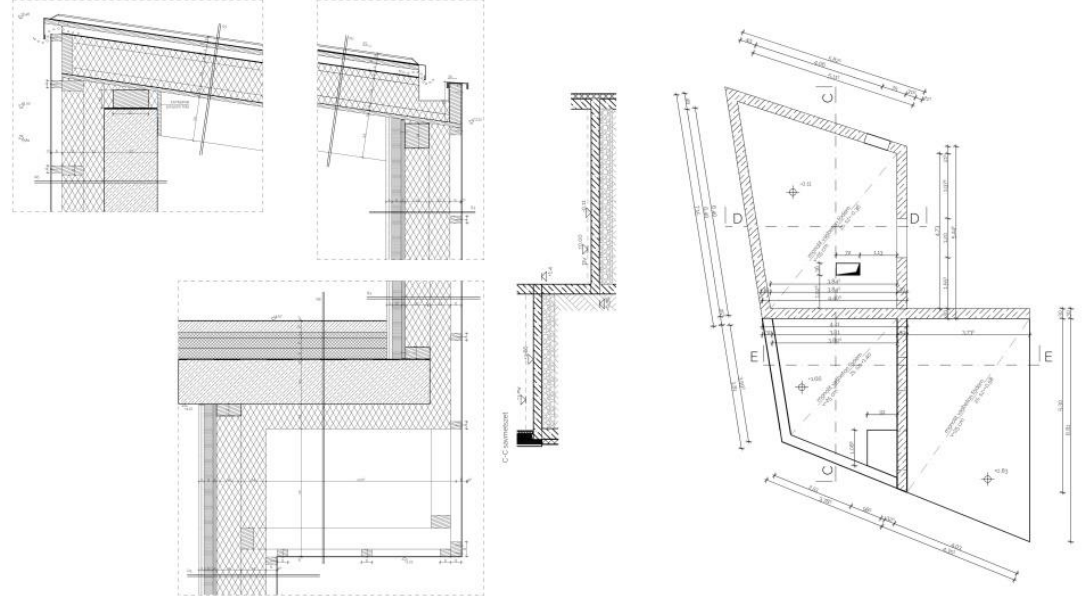

Figure 6. a) Detailed plan of the joints and b) formwork plan of a single-family house [19]

\subsection{Collision detection, quantity statements, and consignments}

In this phase, students got individual subtasks to investigate the model using different aspects. The collision detection was made between the architectural, structural, and mechanical engineering elements by using the Solibri Office software. Based on the results the detected errors were reported and imported back into ArchiCAD using .bcf format and the collisions were corrected. Furthermore, quantity statements were generated for the main structural materials and consignments of the doors, windows, and curtain walls, using the automatized BIM solutions of ArchiCAD. Fabrication plans were generated for the prefabricated concrete structural elements and facade frames of the office building and the timber frame structure of the swimming pool.

\subsection{Preparation of the final documentation of the project}

The final documentation of the projects included the completed architectural plans, the structural analysis, the structural drawings, the collision detection, the quantity statements, and the consignments. During the course, several deficiencies were revealed by the examinations, therefore this final documentation was requested to be submitted and presented in the exam period, leaving some weeks to complete the designs. The groups took the opportunity and improved a lot on their projects, so they could present really good quality work at the end of the semester. 


\section{Discussion}

\subsection{Opinion survey}

To improve the subject in the future, trainers wanted to get feedback from the students based on their experiences, therefore a customized survey was performed in the form of an online questionnaire. The survey was conducted among the students who participated in the course. The questionnaire was received by all students and 10 of 12 students also answered anonymously. The 13-item-long survey focused on the effectiveness of BIM education and the impact of the BIM approach on workflow. The following topics were included in the questionnaire:

- ArchiCAD user skills at the beginning and the end of the course;

- the usefulness of the complex collaborative task;

- the effect of the BIM processing method

- on team communication;

- $\quad$ on the production of design documentation;

- $\quad$ on the structural analysis;

- $\quad$ on the preparation of quantity statements;

- on the design of consignments/element plans;

- on finding and correcting faults;

- the difficulties of applying the BIM working method;

- understanding and experience expansion in BIM during the semester;

- individual ideas for improvement.

According to their first experiences, students find that making the quantity statements, identifying, correcting errors, and designing consignments can be done easier with BIM methods than with the traditional way (Fig. 7.). It is a great achievement because most of the students encountered this processing method this semester firstly, and their software background was also low. Even without special training and practice, this BIM method made the exercises considerably easier. 


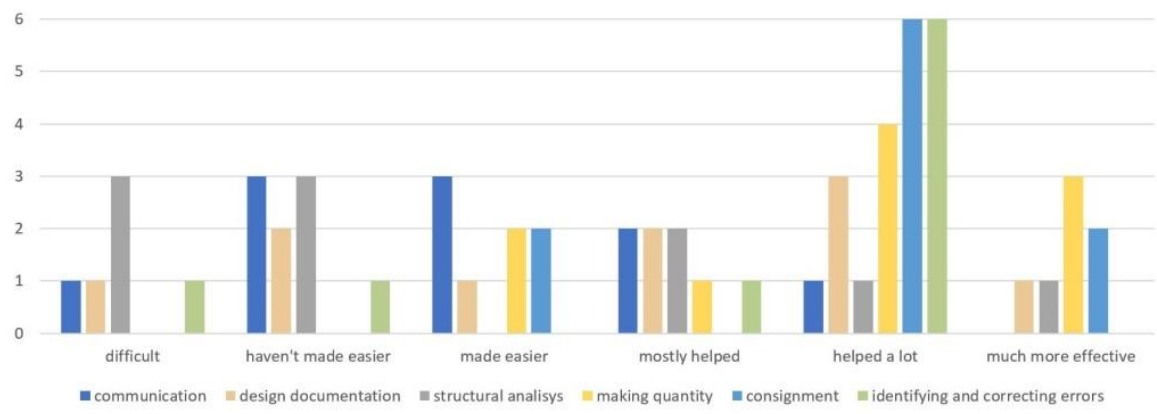

Figure 7. Effect of BIM processing method on the workflow according to the experiences of the students

In the case of interdisciplinary communication, the students' opinions were divided. Some of them thought that this method did not help communication, but others thought that it helped a lot. In this university assignment, it was possible to simulate live project situations, which are often cumbersome and challenging. The pandemic period and the switching to online training forced intensive communication among group members. This problem prepares students also for real life, where working in distance is becoming increasingly necessary.

In the case of preparing the design documentation, the opinion was also controversial. Probably, those who worked on a larger-scale building may have found this job easier. In their case, there was a lot of repetitive work and the BIM method shows a return relatively quickly due to the scale. [20] On the other hand, those who found this method more difficult, probably used fast, non-transparent processing methods in the past (e.g. fill-in corrections on sections, floor plans, documentation hierarchical neglect, etc.). For them, it was more difficult to apply the controlled design processing.

Almost all civil engineers found the BIM-based structural analysis more complicated than the usual method. The biggest challenge was the direct use of the architect model to make the structural analysis. In their previous tasks, they did not depend on the work of others, and they were able to proceed at their own pace and discretion. However, now they also had to deal with the model to be imported, which was a completely new job for them. Importing the BIM model back and forth required close cooperation between the two disciplines to transfer the required data.

Students generally reported that their CAD/BIM skills improved significantly during the course (Fig. 8.). The real-life-based assignment, also the contemporary buildings, and the complex design task were welcomed. This was the first time at the university when architects and civil engineers could work together on one 
common project. All students evaluated the course positively, they also found it useful to see processes like real planning.

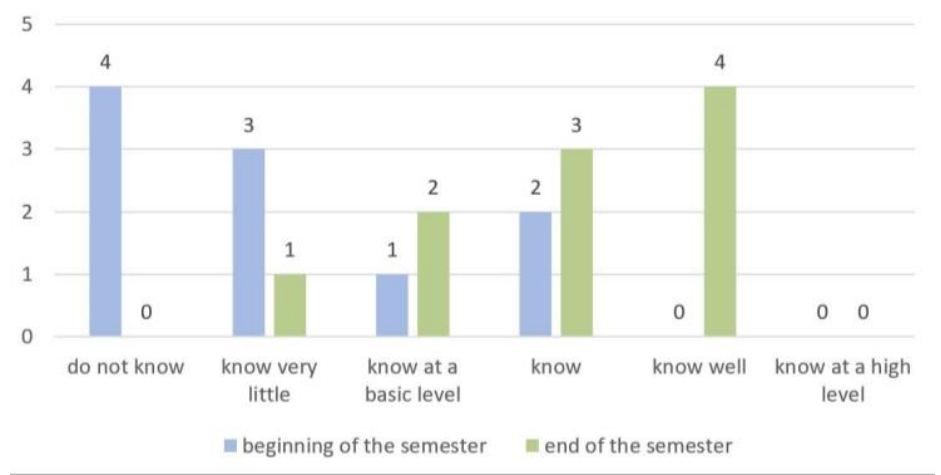

Figure 8. Students' CAD/BIM knowledge at the beginning and end of the semester

\subsection{Trainers' experiences}

However, this new course has some antecedents at the university, organizing a common course for architects and civil engineers was a challenging task and needed a serious collaboration of the departments and trainers. The pioneering course can be concluded as a successful training, but all trainers see the possibilities of improvements, which can be implemented in the next few years. Students attending the course were senior students, but they arrived with different knowledge, experiences, and software skills. One of the biggest problems was the deficiencies in the software skills. The assignment expected a quite good level of ArchiCAD use, but this was not given in the case of all students. ArchiCAD was educated for architects in a compulsory course, but civil engineers can meet this software only in an optional course. These differences should be considered in the future. The modification of the curricula is difficult, therefore the problem may be solved by a course-integrated intensive ArchiCAD training. Experiences of the BIM course can be also considered as feedback for the ArchiCAD courses, where the importance of accurate, rule-following, professional modeling, and design workflow should be emphasized. Practiced software users can also have problems if they are accustomed to improper practice.

In this very first course, the proportions of the distribution of students were not ideal, civil engineers were overrepresented in the groups. In an ideal situation, the members of the two disciplines are balanced. Design of building construction projects employs fewer civil engineers than architects. Hopefully, the ratio will change in the future when more architects will reach the last semester of the new 
BSc training. It was also experienced both from the students' and trainers' side, that BIM is an ideal concept that can help in the design of the built environment, but theory needs a lot of practical solutions. The integration of the BIM aspect into the design is an ongoing process, which requires and holds significant research results soon. These results must be implemented in practical solutions and built into the software. Users, such as designers, must have the intent to learn these new techniques and properly use them. Important learning was that BIM competencies had to be defined by the trainers, and after that, the aims and methods of education can be adapted to the competencies [21].

BIM development levels can be different in different projects or even inside in the case of different subtasks. These levels should be chosen carefully, according to the available software and hardware endowments, and last but not least, according to the available intellectual capacity and labor force.

An important advantage of the course arrangement was the continuous feedback from the development of the projects and the contribution of the participants. The modeling was a common task at the beginning for all team members, which resulted in a higher contribution of the architecture students. After the individual tasks were defined and the students were accountable for their assignments, the contribution of the team members became more balanced. Therefore, these roles and responsibilities should be defined more precisely in the future at the beginning of the course.

\section{Conclusions}

It can be concluded, that the cooperation between the architect, structural and mechanical engineer can be simulated in the university environment, therefore the implementation of BIM into the curricula was successful. Comparing to the traditional design method, with the help of the BIM students get a better understanding of the building and the aspects of the connecting disciplines, though not without its challenges. While in the case of the traditional method the revision of changes in the plans is the most time-consuming task, with the BIM method this work can be made automatically based on the model. Here, the greatest challenge is to create an appropriate model according to the project's purposes and to find the proper way of data exchange between the disciplines. Once this task has been achieved, the BIM method provides many possibilities for further use; the introduced course covers automatic documentation, collision detection, quantity statements, and consignments, therefore it has many development opportunities. In the future, it is also aimed to create cost estimation, use the model in construction management and analyze the efficiency of the different solutions. These applications have even greater importance in the industry, therefore their integration into higher education improves the students' competencies and prepare them for the current challenges of 
the industry. It can be concluded, that students' interests were raised in a developing area that will certainly have an impact on their work. Some of them started working on a BIM-related topic as a thesis work, which gives them more freedom to explore the common points between disciplines.

\section{References}

[1] K. Zima, E. Plebankiewicz, D. Wieczorek, A SWOT analysis of the use of BIM Technology in the Polish construction industry, Buildings 10 (1):16 (2020)

doi: https://doi.org/10.3390/buildings10010016

[2] MSZ EN ISO 19650:2019 Organization and digitization of information about buildings and civil engineering works, including building information modeling (BIM). Information management using building information modelling

[3] T. Horváth, Project-based education of building construction design for architects, Hazai és külföldi modelek a projektoktatásban, Óbuda University, Budapest, Hungary (2017) pp. 134-142, in Hungarian

URL https://www.researchgate.net/publication/317193175

[4] A. Shibani, S. B. Souliman, BIM Implementation Strategies in Higher Education (Case Study Coventry University) pp. 406-420.

URL http://www. ieomsociety.org/ieomuk/papers/92.pdf

[5] A. Abbas, Z. U. Din, R. Farooqui, Integration of BIM in construction management education: an overview of Pakistani Engineering universities, International Conference on Sustainable Design, Engineering and Construction, Procedia Engineering 145 (2016) pp. 151-157.

doi: https://doi.org/10.1016/j.proeng.2016.04.034

[6] X. Zhang, R. Jin, T. Yang, Review of BIM Adoption in the Higher Education of AEC Disciplines, Journal of Professional Issues in Engineering Education and Practice 146 (3):06020001 (2020)

doi: https://doi.org/10.1061/(ASCE) EI.2643-9115.0000018

[7] K. Rooney, BIM Education - Global Summary 2015 Update Report, Sydney, Australia, NATSPEC Construction Information, 2015.

URL https://icis.org/wp-content/uploads/2017/11/ICIS2015BIM_Education_Global_2015_Update_Report_V2.0.pdf 
[8] L. Wang, X. Yan et al., Incorporating BIM in the Final Semester Undergraduate Project of Construction Management-A Case Study in Fuzhou University, KSCE Journal of Civil Engineering (2020) in PressDetail, 5 (2019).

doi: https://doi.org/10.1007/s12205-020-1971-4

[9] A. C. Badrinath, Y. Chang, P. Hshieh, A review of tertiary BIM education for advanced engineering communication with visualization, Visualization in Engineering 4:9 (2016).

doi: https://doi.org/10.1186/s40327-016-0038-6

[10] K. Baradi, M. Oraee et al., Teaching collaboration in tertiary BIM education: A review and analysis, The 42nd Australasian Universities Building Education Association (AUBEA) Conference Proceedings, Singapore, 2018. URL https://minervaaccess.unimelb.edu.au/bitstream/handle/11343/230682/Oraee .pdf? sequence $=2 \&$ is sllowed $=y$

[11] K. Chen, W. Lu, J. Wang, University-industry collaboration for BIM education: Lessons learned from a case study, Industry and Higher Education 34 (6) (2020) pp. 401-409.

doi: https://doi.org/10.1177/0950422220908799

[12] C. Merschbrock, M. R. Hosseini et al., Collaborative Role of Sociotechnical Components in BIM-Based Construction Networks in Two Hospitals, Journal of Management in Engineering 34 (4):05018006 (2018).

doi: https://doi.org/10.1061/(asce)me.1943-5479.0000605

[13] U. Poerschke, R. J. Holland et al., BIM collaboration across six disciplines (2010) Proc. of the Int. Conf. on Computing in Civil and Building Engineering, Nottingham University Press.

URL https://www.researchgate.net/publication/280087526

[14] MVRDV, Office building in Amsterdam, Detail 5 (2019) pp. 56-59.

[15] Hawkins/Brown, School swimming pool near London, Detail 7/8 (2019) pp. 48-53.

[16] Yonder - Architektur und Design, Single-family house in Tuttlingen, Detail 10 (2019) pp. 54-59. 
[17] E. Szabó, E. Schram et al., Construction plans for the MVRDV: Office building in Amsterdam, 2021.

[18] Zs. Kalmár, P. F. Módy et al., Construction plans for the Hawkins/Brown: School swimming pool near London, 2021.

[19] Sz. Dugár, M. Bak et al., Construction plans for the Yonder: Single-family house in Tuttlingen, 2021.

[20] A. J. Garcia, S. Mollaoglu, M. Syal, Implementation of BIM in Small HomeBuilding Businesses Practice Periodical on Structural Design and Construction 23 (2): 04018007 (2018).

doi: https://doi.org/10.1061/(ASCE) SC.1943-5576.0000362

[21] S. Kolarić, T. Mandičák et al., BIM training in construction management educational practices in Croatia and Slovakia, Creative Construction Conference, Ljubljana, Slovenia, 2018, pp. 1002-1009.

doi: https://doi.org/10.3311/CCC2018-130 